Rhode Island College

Digital Commons @ RIC

$4-22-2021$

\title{
Compassion Fatigue in Critical Care Nurses: An Educational Quality Improvement Project
}

Natasha Teixeira

Follow this and additional works at: https://digitalcommons.ric.edu/etd

Part of the Critical Care Nursing Commons

\section{Recommended Citation}

Teixeira, Natasha, "Compassion Fatigue in Critical Care Nurses: An Educational Quality Improvement Project" (2021). Master's Theses, Dissertations, Graduate Research and Major Papers Overview. 391.

https://digitalcommons.ric.edu/etd/391

This Major Paper is brought to you for free and open access by the Master's Theses, Dissertations, Graduate Research and Major Papers at Digital Commons @ RIC. It has been accepted for inclusion in Master's Theses, Dissertations, Graduate Research and Major Papers Overview by an authorized administrator of Digital Commons @ RIC. For more information, please contact digitalcommons@ric.edu. 
Compassion Fatigue in Critical Care Nurses: An Educational Quality Improvement Project

by

Natasha M. Teixeira

A Major Paper Submitted in Partial Fulfillment

of the Requirements for the Degree of

Master of Science in Nursing

Rhode Island College School of Nursing

2021 


\begin{abstract}
Compassion fatigue is estimated to affect $40 \%$ percent of the 2.9 million registered nurses in the United States. There exists a critical need to explore how nurses understand compassion fatigue, how they identify it in self and others, and what strategies they enact to lessen the eventual threats to health. With the current COVID pandemic, along with the high intensity nature of the intensive care unit (ICU), critical care nurses are vulnerable to the symptoms and side effects of compassion fatigue. This quality improvement project evaluated the impact of an educational session on compassion fatigue and self-care in relation to critical care nurses' perceived levels of compassion fatigue. Pre education session and post educational session Professional Quality of Life (ProQOL-5) survey measuring perceived levels of compassion satisfaction, burnout, and secondary traumatic stress, were administered to a sample of critical care nurses in a community hospital in Massachusetts. The educational session was conducted via a virtual audio-enabled PowerPoint presentation. Pre and post education scores were assessed between time points to determine if the education was successful at decreasing perceived level of compassion fatigue. Post ProQOL scores presented a $6.76 \%$ increase in level compassion satisfaction, $3.28 \%$ decrease in level of burnout, and an $8.66 \%$ decrease in level of secondary traumatic stress. This project illustrates the potential for targeted education with critical care nurses as a vulnerable group who experience higher levels of compassion fatigue as a group. Strategies to reduce the effects of compassion fatigue have the potential to improve mental and emotional health essential for continual safe patient care with more positive outcomes in the critical care area.
\end{abstract}




\section{Acknowledgements}

I would like to give my sincere appreciation for all the healthcare workers

throughout the United States, who continuously sacrifice themselves for the betterment of others. Your continued dedication to high quality patient care does not go unnoticed. To the healthcare workers who participated in this study, I could not have completed this project without you. I would also like to offer thanks to the staff at Rhode Island College for their continued support throughout the development of this project. I would like to specifically acknowledge Dr. Sadlon, Dr. Misto, Muriel Natsis and Dr. Hodne for without their assistance this project would not have come to fruition. Most of all I would like to extend recognition to my husband, father, brother, and my mother in heaven for always believing in me and supporting me throughout every step of my educational journey. 


\section{Table of Contents}

Background/Statement of the Problem.........................................

Literature Review.........................................................4

Theoretical Framework......................................................... 13

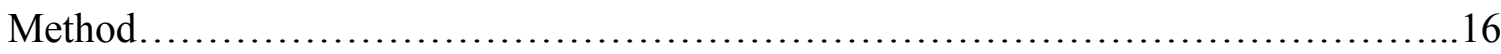

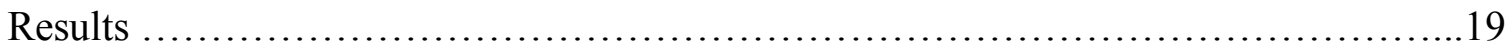

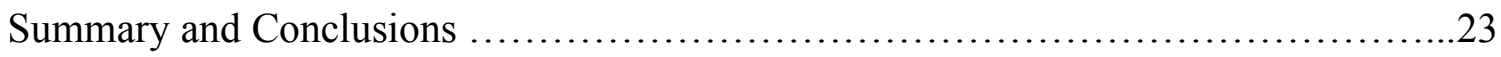

Recommendations and Implications for Advanced Nursing Practice .................24

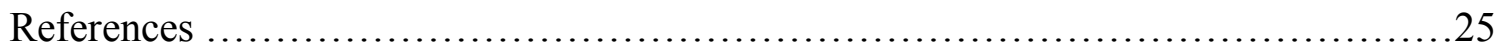

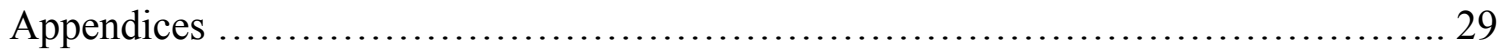


Compassion Fatigue in Critical Care Nurses: An Educational Quality Improvement Project

\section{Background and Problem Statement}

Forty percent of the 2.9 million registered nurses in the United States suffer from compassion fatigue a psychological syndrome that has negative physical, emotional, and behavioral side effects (Perregrini, 2019). Lack of compassion within the healthcare system is estimated to cost the U.S. \$100-\$300 billion annually. New research exploring compassion fatigue indicates that critical care nurses are the most vulnerable (Perregrini, 2019). Critical care nurses are at risk for developing compassion fatigue due to the high intensity environment of the critical care unit. Patients in these units are severely ill with life threatening complications, and their status can change suddenly. Compassion fatigue occurs when critical care nurses are continuously exposed to traumatic events. These exposures accumulate causing an emotional disconnection from the situations around them in the workplace. This results in decreased empathy, increased anxiety and depression, and compassion fatigue, which often translates into poor patient outcomes. However, we also know that decreasing compassion fatigue in nurses improves patient outcomes and promotes quality patient care (Gonzalez, 2016).

Compassion fatigue is defined as a prevalent emotional state known to negatively impact the patient and critical care nurse relationship (Balinbin, 2019). Compassion fatigue affects the quality of care given to patients through increased medical errors and failure to rescue (Trzeciak, 2019). Compassion is the cornerstone to health care (Peters, 2018), yet evidence suggests that $64 \%$ of patients in the U.S. reported lack of compassion in their experience with the health care system. Lack of compassion within healthcare 
delivery systems is linked to higher healthcare costs, poor patient satisfaction, and the absence of caring - an essential element in nursing's humanistic approach.

Compassion fatigue has been researched in the caregiving professions, such as emergency personnel, nurses, physicians, social workers, chaplains, psychologists, and genetic workers (Coetzee \& Laschinger, 2017). Compassion fatigue is influenced by levels of perceived stress and repeated traumatic events experienced by critical care nurses. As reported by Rosch et al. (2013), 74\% of healthcare employees report that work is a significant source of stress in their lives, and one in five healthcare workers have missed work because of the stress. Fifty-five percent of health care workers reported they are less productive at work because of the stress of their job. Stress-related compassion fatigue is associated with missed workdays, high turnover rate, and diminished productivity (Rosch, et al., 2013). As critical care nurses' workloads and responsibilities increase, perceived stress levels increase leading to increased risk of compassion fatigue.

The current compassion crisis negatively affects all stakeholders of the health care system. Compassion is an essential factor for delivering high-quality and safe nursing care. In the critical care unit, critical care nurse's witnessing of repeated suffering increases their risk for the development of compassion fatigue. The critical care nurse may then experience depersonalization of the nurse-patient relationship and fail to develop meaningful connections with patients. Research suggests $79 \%$ of patient's emotional cues were missed by health care providers indicating lost opportunities for compassionate care (Trzeciak, 2019). Health care providers, including nurses, are too involved in extraneous aspects of care, such as documentation, that providers fail to 
notice and attend to what the patient is attempting to verbalize (Trzeciak, 2019). This results in deterioration of the nurse-patient relationship, missed opportunities for quality care, and higher health care costs associated with patient non-adherence, missed specialist referrals, and re-hospitalizations (Viswanathan, et al., 2012). Healthcare needs compassionate nurses who bring the human element of caring back into the patient nurse relationship. 


\section{Literature Review}

\section{Search Strategy}

Databases of EBSCOhost, CINHAL, and Medline were accessed for articles published between 2010-2020. Search terms included compassion fatigue and critical care. Only full text articles in English were included for further review. Studies reporting the prevalence of compassion fatigue in the intensive care unit (ICU) and interventional studies regarding the importance of self-care are included. Twenty-one articles were kept for review. Articles that were not written in English and written prior to 2010 were excluded.

\section{Definition of Compassion Fatigue and Its Consequences}

The word compassion has an historical origin dating back to 1400-1500 B.C. when biblical authors described the actions of baby Moses' journey in the Bible (Coetzee \& Laschinger, 2017). The concept of compassion fatigue was first theoretically described by Carla Joinson in 1992. The term was used initially to describe nurses who had disconnected from or had become desensitized to, patients and families creating high levels of stress and anxiety in their nursing environment (Joinson,1992). Compassion fatigue is defined as the progressive and cumulative outcome of prolonged, continuous, and intense contact with patients, self-utilization, and exposure to multidimensional stress leading to a compassion discomfort that exceeds nurse's endurance levels (Coetzee \& Klopper, 2010). Compassion fatigue occurs when "the compassionate energy that's been expended has surpassed restorative capabilities and originates in witnessing suffering and a feeling of impotence to do more to help the other person" (Boyle, 2015 p. 50). Throughout the literature compassion fatigue is commonly referred to as the cost of 
caring (Sorenson et al., 2017). Cocker and Joss (2016) explain that compassion fatigue triggers a stress response both physically and mentally.

Compassion fatigue creates an emotional toll to caregivers. Providing patient care becomes emotionally, physically, socially, and spiritually exhausting, which causes desensitization, apathy, or depersonalization for others (Henson, 2020). Healthcare workers at highest risk for developing compassion fatigue have witnessed repeated trauma to others and are more likely to develop a lack of emotional connection to future similar situations (Sorenson et al., 2017). Compassion fatigue can be described further as the subsequent loss of meaningful and fulfilling interactions between patients and caregivers (Coetzee \& Laschinger, 2017). A lack of fulfillment through meaningful interaction takes away personal satisfaction from the occupation leading to increased levels of compassion fatigue (Coetzee \& Laschinger, 2017).

\section{Indicators of Compassion Fatigue}

Indicators of compassion fatigue can extend well beyond physical characteristics, including emotional and behavioral deficits. Harris and Griffin (2015) suggest symptoms of compassion fatigue may also have an impact on caregiver's performance. Harris and Griffin's analysis on compassion fatigue present antecedents and consequences of the concept. Antecedents include minimal or no spiritual commitment, emotional investment, lack of personal and professional support systems, and lack of inner conviction and resiliency. Consequences described include poor clinical judgment, errors in providing high quality care, patient dissatisfaction, and decreased discernment and quality of care. 


\section{Physical}

Physical indicators of compassion fatigue include exhaustion, frequent headaches, gastrointestinal complaints, hypertension, chest pain or tachycardia, sleep disturbances, muscle tension, frequent or lingering illness, or anxiety (Sorenson et al., 2017).

\section{Behavioral}

Behavioral indicators of compassion fatigue may include the inability to maintain balance of empathy and objectivity, chronic lateness, overworking, exaggerated startle responses, difficulty focusing and concentrating, substance abuse, eating disturbances, avoiding or dreading work, and frequent absenteeism (Sorenson et al., 2017). Emotional changes include emptiness, diminished sense of personal accomplishment, decreased sense of purpose, less ability to feel joy or happiness, low self-esteem, high selfexpectations, hopelessness, numbness, disinterested and detached, apathy, anger, irritability, and depression.

\section{Compassion Fatigue: Related Concepts}

Interchangeable terms and related concepts to compassion fatigue include burnout, secondary traumatic stress disorder, also known as vicarious traumatization, and moral distress. Burnout is related to an assertiveness-goal achievement response and occurs when an individual cannot achieve his or her goals (Cocker \& Joss, 2016). Alternatively, secondary traumatic stress disorder differs from compassion fatigue mostly by involving a failed attempt to rescue, leading to guilt and mental distress. More precisely, these related terms are consequences of compassion fatigue. Stamm (2010) describes the differences between burnout and secondary traumatic stress distinguishing the term outcomes from exposure to repeated psychological trauma — now known as 
compassion fatigue.

\section{Burnout}

Burnout is defined as an emotional and behavioral impairment that results from exposure to high levels of occupational stress (van Mol et. al, 2015). Factors contributing to burnout include workload, autonomy, and personal relationships. While factors contributing to compassion fatigue include inability to engage or enter a caring relationship (Boyle, 2015). This varies from the definition of compassion fatigue as a state of physical or psychological distress on caregivers, which occurs as a consequence of being in a demanding relationship with challenging individuals affecting those with high levels of perceived self-perfectionism (van Mol, et al., 2015). Individuals relate their work to failure, creating a gap between satisfaction and work, which leads to a negative view of their workplace and decreases workplace morale. Compassion fatigue differs in origination of burnout in the sense that burnout relates to individual professional goals, whereas compassion fatigue describes the overall sense of failure with the inability to help those in need.

\section{Moral Distress}

Moral distress relates to the ethics of the nursing profession. Moral distress is characterized in the psyche when a course of action is known, but cannot be acted upon (Gonzalez, 2016). In the critical care setting moral distress is often present in interactions between the nurse and patient due to the complexity of decision making in a high-acuity high-mortality environment. Mason et al. (2014) reported that $65 \%$ of the surgical intensive care nurses reported having moral distress related to their occupation. Mason and colleagues mixed-methods study examined the relationship between-compassion 
satisfaction, compassion fatigue, and moral distress. Qualitative questions, such as, "Do nurses identify themes in their work-related experience?", elicited seven themes including the role conflict with management/rules, death and suffering end of life decision making, dealing with violence in the ICU, dealing with family, powerlessnessmoral distress, physical distress, and medical versus nursing values-moral distress (Mason, et al., 2015). Prevalence of moral distress within the critical care setting is profound, decreasing nurse's job satisfaction and making them susceptible to compassion fatigue. In Cimiotti, et al., (2012), evidence suggests an association between hospitalacquired infections, such as urinary tract infections and surgical site infections, and nurse's level of burnout and moral distress. When methods to decrease nurse's levels of burnout and moral distress were implemented, a noted reduction of $30 \%$ of hospitalacquired infections, and led to a \$68 million savings (Gonzalez, 2016).

\section{Secondary Traumatic Stress}

Psychological distress is a state of emotional suffering, characterized by symptoms of anxiety and depression (Christodoulou-Fella, et. al, 2017). Occupational stress, a subtype of psychological stress, occurs because of repeat exposure to events in the workplace, such as secondary traumatic stress disorder. Secondary traumatic stress disorder (STDS) is described as the inadvertent trauma experienced by hearing or dealing with survivors of trauma causing both psychological and physical ailments, sleep disturbances, intrusive images, and avoidance of situations relating to the client's trauma. Compassion fatigue can be distinguished from STDS in that STDS occurs psychologically when reliving someone else's trauma, while compassion fatigue occurs when the individual experiences a disconnection after multiple insults and the individual 
cannot find joy and meaning in providing care to patients (Winters, 2018). Typically, untreated STDS develops into compassion fatigue.

\section{Compassion Fatigue in Critical Care Nursing}

Critical care nurses provide care to those who are critically ill with lifethreatening acute illnesses or injuries. In 2015 the American Association of Critical Care Nurses (AACN) recognized the burden of compassion fatigue on the emotional, personal, and professional well-being of critical care nurses. In Nolte et al. (2017), a meta-synthesis on compassion fatigue in nursing revealed four themes as: physical symptoms, emotional symptoms, triggering factors, and measures to prevent compassion fatigue. The common theme-described as burden of caring impacted nurses' capacity to complete their workrelated duties and created a detrimental impact on their personal lives (Nolte et al., 2017). Physically, nurses reported feeling just plain worn out and so physically tired they felt empty. The emotional impact was described by nurses as if they were walking on a tightrope. It was found that positive coping and less compassion fatigue existed in nurses who could verbalize their feelings with others.-Factors that triggered compassion fatigue, included nurses' work as an unbearable weight on their shoulders, and feeling alone in a crowded room.

Sacco et al (2015) found a paucity of existing evidence concerning critical care nurses and compassion fatigue. Sacco and colleagues reported disproportions of compassion satisfaction and compassion fatigue suggesting compassion satisfaction could be perceived as a positive experience occurring from caring for those in life threatening illness. Using the ProQOL scale to determine levels of compassion fatigue, burnout, and compassion satisfaction, Sacco et. al found that more experienced nurses scored the 
highest on compassion satisfaction and lower on compassion fatigue scaled compared to their younger colleagues. Older nurses have the skill set and experience needed to overcome the challenges of intensity of critical care nursing, while also being able to connect the impact that their care has on patients. Conversely, younger nurses in the critical care setting are more vulnerable to compassion fatigue, therefore increased precautions and education is needed in this population. Suggested measures to prevent compassion fatigue-included greater support from institutions, peer counseling, exercise, and increased awareness regarding compassion fatigue in the workplace (Nolte, et. al., 2017).

Van Mol et. al (2015) systematic review of the prevalence of compassion fatigue and burnout among critical care nurses found compassion fatigue prevalence between $7.3 \%$ to $40 \%$, and burnout between $1.2 \%$ and $23 \%$, representing a broad range of compassion fatigue with various associated factors. Recommendations to decrease compassion fatigue include enlisting psychologists to provide emotional care after traumatizing events, educational programs aimed at compassion fatigue and burnout recognition, relaxation exercises, and training on end-of-life (EOL) care and ethics in the ICU. When these strategies were implemented, reduction of $50-60 \%$ of perceived symptoms of burnout and compassion fatigue were attained (von Mol et al., 2015; Appendix A). In another example, Todaro-Franceschi (2013) studied the relationship between basic nursing education preparedness and the ability of the critical care nurse to provide EOL care. They found those suffering from compassion fatigue exhibited behavioral, emotional, and physical signs and symptoms and that nurses' professional quality of life were impacted by their perceptions. For those nurses who responded as 
feeling prepared for EOL issues, study results indicated lower compassion fatigue, higher compassion satisfaction scores, and lower burnout scores (Todaro-Franceschi, 2013). Implications for practice to avert compassion fatigue then demand compassion fatigue education for nurses and establishment of interventions that promote professional nurse satisfaction.

\section{Importance of Self-Care}

Self-care promotes a healthy mind, body, and spirit, and self-care habits are needed to prevent or at least minimize the effects of burnout and compassion fatigue (Vivian, et al., 2019). The World Health Organization (WHO) defines self-care as the process by which an individual positively promotes health, prevents disease, maintains health, and copes with illness and disability. Fundamental principles for self-care include self-reliance, empowerment, autonomy, personal responsibility, self-efficacy, in addition to the promotion of greater community participation, involvement, and empowerment (WHO, 2019). Self-care strategies include mindfulness, guided imagery, and other activities one finds as a mental escape to find peace. Self-care in nursing is described by the American Nurses Association (ANA, 2017) as the capacity to promote and maintain personal health, safety, and wellness. When nurses practice self-care patient satisfaction and nurse satisfaction rise (Vivian, 2019). Nurses who described their level of self-care as low are $26-71 \%$ more likely to make medical errors compared with their counterparts practicing good self-care (Melnyk, et. al, 2018). Vivian and colleagues (2019) also found that the higher level of stress a nurse endures the lower amount of patient satisfaction ratings given by their patients. Therefore, this study primarily focuses on educating 
nurses to decreased their perceived levels of compassion fatigue and improve the quality of patient care. 


\section{Theoretical Framework}

\section{Figley's Compassion Stress and Fatigue Model}

Figley's (2001) Compassion Stress and Fatigue Model illustrates the importance of emotion and empathy in the creation of a therapeutic relationship between the patient and caregiver (Appendix A). Figley found the same characteristics that strengthen the emotional aspects of the nurse patient relationship can also negatively affect the caregiver in their own personal lives. The caregiver's initial empathetic concern creates an empathetic response creating a sense of duty to connect with the patient. Over time, the caregiver can suffer feelings of disengagement from repeated emotional wounds and eventual compassion stress. Figley's theory of compassion fatigue has become foundational in understanding compassion fatigue as a prevalent and legitimate emotional side effect of empathetic and caring relationships with patients. Using the theoretical premises from Figley's model, Carroll (2017) reported interventions that have the potential to mitigate caregiver stress and promote the symbiotic nurse-patient experience. Figley's model provided the foundation for understanding compassion fatigue, and why critical care nurses are particularly exposed through their work. Targeting specific points in development of compassion fatigue, (see Appendix A), this model helps conceptualize the development of the compassion fatigue that is experienced by critical care nurses. 


\section{Methods}

\section{Purpose}

The purpose of this quality improvement project is to assess critical care nurses' perceived level of compassion fatigue, and to provide an educational session to critical care nurses about compassion fatigue.

\section{Design}

Permission from The Center for Victims of Torture to use the Professional Quality of Life Scale (ProQOL-5)(Stamm, 2010) was obtained per the organization's regulations (See Appendix F). The ProQOL was administered via a Qualtrics link to a participant group of nurses $(\mathrm{N}=34)$ at a community hospital in Massachusetts. The ProQOL is a validated and a reliable tool (Cronbach's $\alpha=0.90)$ used throughout the literature to assess compassion satisfaction, burnout, and secondary traumatic stress. Compassion satisfaction, burnout, and secondary traumatic stress are domains impacting levels of compassion fatigue. The pre-education ProQOL survey served as a baseline of the nurse's current perceived levels of compassion fatigue. Nurses were then asked to participate in an educational session regarding compassion fatigue completed via a virtual audio-enabled PowerPoint presentation. Questions were encouraged and addressed via email. A post ProQOL survey was then administered one-week later to the nurses after the educational session to determine the impact of the educational session on their perceived levels of compassion fatigue.

\section{Sample and Setting}

Convenience sampling was used in this quality improvement project. The ProQOL survey was collected anonymously via Qualtrics to protect participants. Each 
study participant was asked to create a unique private identifier to further protect their survey results. Only the researcher and advisor had access to the surveys with a locked password. Participant demographics were not asked to protect participant confidentiality.

\section{Inclusion criteria}

All 75 critical care registered nurses at a 396-bed community hospital in Massachusetts were eligible to participate.

\section{Exclusion criteria}

Exclusion criteria include ancillary staff, management or administrative staff, participants under the age of eighteen, and registered nurses currently on orientation in any of the participating units. Participants who only completed one survey did not provide a unique user ID or entered a new different user ID as the first survey were excluded from this study. This was due primarily to being unable to measure the efficacy of the education they received on their perceived level of compassion fatigue.

\section{Approval and Ethical Considerations}

Data collection began once approval from Rhode Island College Institutional Review Board (IRB)\# 2021-2122 was completed. Administrative endorsement from the study site hospital and nurse manager of critical care unit was obtained, and the organization approved the implementation of this study at their institution. Qualtrics data was kept confidential with a user specific PIN created by the study participants. Qualtrics is a locked organizational and user specific portal. 


\section{Methods}

\section{Professional Quality of Life (ProQOL)}

The ProQOL-5 (Stamm, 2010) scale consists of thirty Likert style questions that have the participant reflect on positive and negative aspects regarding their current work situation within the last thirty days. The survey is estimated to take each participant less than ten minutes to complete. The scale consists of thirty questions that allow the participant to reflect and evaluate the frequency and intensity of compassion fatigue in their daily work. The domains of compassion satisfaction, burnout, and secondary traumatic stress are addressed in the ProQOL. A score of 22 or less in each category is indicative of a low level in that category. A score of 23 to 41 is indicative of moderate level in that category. A score of 42 or more in that category is indicative of prominent level in that category (Appendix E).

The ProQOL scale has been used to quantitatively describe the level of compassion fatigue experienced by health care professionals in relation to the negative and positive effects of caregiving professions (Heritage et al., 2018). The scale questions individuals on various areas including impact of experiences on emotional wellbeing, and the satisfaction of their work they experience (Stamm, 2016). This tool has been shown to be valid and reliable (Cronbach's $\alpha=0.90$ ) throughout all specialties of nursing, therefore increasing its popularity in the study of compassion fatigue (Mattioli, et. al, 2018). Heritage et al. reported the validity and reliability of the ProQOL 5 (Cronbach's $\alpha=0.90$ ) used with 1615 registered nurses. These authors report with item response and invariance testing the ProQOL successfully measures compassion fatigue and compassion satisfaction. 


\section{Data Collection}

Once permission was attained from the RIC IRB (Institutional Review Board) and hospital ethics committee, critical care nurses at a community hospital in Massachusetts were notified of their invitation to participate in this project via their institution's e-mail and a flyer (Appendix C; D). The e-mail letter included a link to the Qualtrics ProQOL survey questions. Each participant created a user specific code (e.g., 100893NT) to access the survey. Waived consent (implied) was assumed if the nurse completed the surveys. All of nurses on the unit then received a follow up e-mail that had the educational session as an attachment with audio-enabled PowerPoint slide presentation. Participants were then asked to repeat the ProQOL after the educational session. Comparison of the preeducation ProQOL score and the post-education ProQOL score was completed to determine if the educational session decreased their level of perceived compassion fatigue.

\section{Educational Session}

The educational session objectives included understanding the definition of compassion fatigue, comprehending the burden of compassion fatigue on the health care system, describing signs and symptoms of compassion fatigue, understanding related concepts of compassion fatigue, assessing compassion fatigue in a colleague, understanding the importance of self-care, and creating individual self-care strategies for relief of compassion fatigue. Information regarding compassion fatigue: clinical significance, signs and symptoms, and impact on the quality of patient care. Relief techniques that promote self-care and reduce compassion fatigue were also discussed in the educational session. Nurses were then invited to ask questions regarding the 
education to be implemented in their practice, which were addressed via e-mail. A brief five question education session evaluation was given to the participants to assess the quality of the session and provide feedback. Nurses were also provided on site clinical resources for emotional support if the education triggered unexpected emotions. Participants were then asked to repeat the ProQOL one week after the educational session. 


\section{Results}

\section{Pre-Education Results}

The pre-education ProQOL survey (Figure 1) had a total of 34 participating nurses, however six were ineligible to the study. Four had incomplete surveys, and two did not have a unique user ID, leaving N=28. Pre-educational ProQOL survey results found an average score of 35.5 (moderate) for compassion satisfaction, 27.3 (moderate) for burnout, and 28 (moderate) for secondary traumatic stress.

\section{Figure 1}

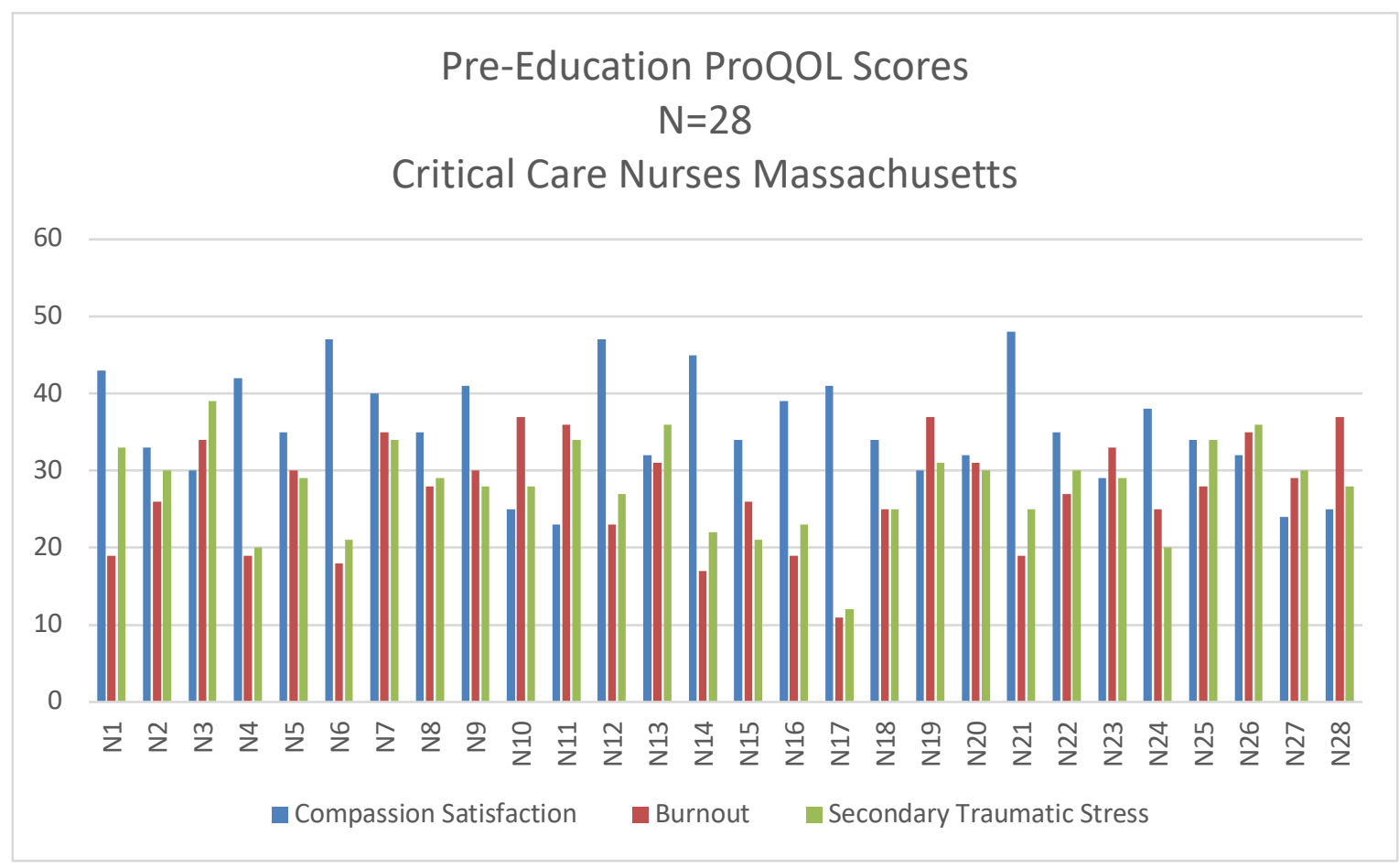




\section{Educational Session Results}

A total of 17 nurses participated in the educational session. Post evaluation scores for the quality of material covered in the education session suggests objectives (providing education on a clinical problem, having quality, and easily understood information, educating nurses on the topic, having nurses assess symptoms of compassion fatigue in themselves, understanding self-care strategies to decrease their symptoms) were met (Figure 2). As $70.59 \%$ of nurses endorsed "strongly agreed" the presentation offered them insight to a clinical problem unaware to them; $94.12 \%$ of the nurses endorsed "strongly agreed" that compassion fatigue is an under recognized problem in the critical care setting. These scores are supported by the literature illustrating a knowledge gap in the clinical setting on compassion fatigue and more education is needed.

\section{Figure 2}

\begin{tabular}{|c|c|c|c|c|c|c|c|c|c|c|}
\hline Question & Minimum & Maximum & Mean & $\begin{array}{l}\text { Standard } \\
\text { Deviation }\end{array}$ & Variance & $\begin{array}{c}\text { Strongly } \\
\text { Agree }\end{array}$ & $\begin{array}{c}\text { Somewhat } \\
\text { Agree }\end{array}$ & $\begin{array}{l}\text { Neither } \\
\text { Agree nor } \\
\text { Disagree }\end{array}$ & $\begin{array}{c}\text { Somewhat } \\
\text { Disagree }\end{array}$ & $\begin{array}{l}\text { Strongly } \\
\text { Disagree }\end{array}$ \\
\hline $\begin{array}{l}\text { Q1: This presentation about } \\
\text { compassion fatigue offered } \\
\text { me insight to a clinical } \\
\text { problem that I was unaware. }\end{array}$ & 1 & 5 & 1.47 & 0.98 & 0.96 & $70.59 \%$ & $23.53 \%$ & $0 \%$ & $0 \%$ & $5.88 \%$ \\
\hline $\begin{array}{l}\text { Q2: This presentation about } \\
\text { compassion fatigue had } \\
\text { quality information that was } \\
\text { easily understood. }\end{array}$ & 1 & 2 & 1.18 & 0.38 & 0.15 & $82.35 \%$ & $17.65 \%$ & $0 \%$ & $0 \%$ & $0 \%$ \\
\hline $\begin{array}{l}\text { Q3: After listening to this } \\
\text { presentation about } \\
\text { compassion fatigue I have a } \\
\text { greater understanding of the } \\
\text { topic. }\end{array}$ & 1 & 3 & 1.29 & 0.57 & 0.33 & $76.47 \%$ & $17.65 \%$ & $5.88 \%$ & $0 \%$ & $0 \%$ \\
\hline $\begin{array}{l}\text { Q4: I feel that compassion } \\
\text { fatigue is an under } \\
\text { recognized problem in the } \\
\text { critical care setting. }\end{array}$ & 1 & 2 & 1.06 & 0.24 & 0.06 & $94.12 \%$ & $5.88 \%$ & $0 \%$ & $0 \%$ & $0 \%$ \\
\hline $\begin{array}{l}\text { Q5: By the end of this } \\
\text { presentation I feel more } \\
\text { prepared to recognize } \\
\text { symptoms of compassion } \\
\text { fatigue and understand some } \\
\text { relief techniques available to } \\
\text { me. }\end{array}$ & 1 & 2 & 1.13 & 0.33 & 0.11 & $87.50 \%$ & $12.50 \%$ & $0 \%$ & $0 \%$ & $0 \%$ \\
\hline
\end{tabular}




\section{Post-Education Results}

\section{Limitations}

Limitations of this project included a small eligible sample population. Various notification methods and the virtual presentation may have reduced participation, as well as time constraints to complete the education session amid the hectic and high acuity nature of the ICU. Another possibility may be related to COVID-19 patients hospitalized at the time of the project preventing critical care nurses' focus and attention on the project. This might also suggest their level of burnout as critical care nurses might be unable to participate completely as attention competes with the high intensity of the workplace. Once the pandemic has subsided further assessment and evaluation is recommended.

\section{Final Results}

Of the 28 nurses who participated in the Pre-Education Survey, nine (32\%) completed all project elements. For the first ProQOL 75 registered nurses employed by the critical care unit 34 nurses $(45.3 \%)$ attempted participation in the study. This sample participated in the first ProQOL, however ultimately only 9 nurses completed the full criteria (Pre-education ProQOL, compassion fatigue education, and Post-Education ProQOL). There were several challenges presented regarding the lost to follow up sample, which created limitations for this study. Results of the sample who fully participated in this study yielded an $6.76 \%$ increase in compassion satisfaction scores, $3.28 \%$ decrease in burnout score, and an $8.66 \%$ decrease in secondary traumatic stress score in participants after the educational session. The data indicates that as nurses were educated about compassion fatigue their perceived levels of compassion fatigue 
decreased supporting the assumption of targeted strategies to increase awareness of compassion fatigue, and the value placed on learning about self-care strategies. Although the data suggests a positive correlation between education of compassion fatigue and decreased symptoms of compassion fatigue, more research is needed to confirm this relationship.

\section{Figure 3}

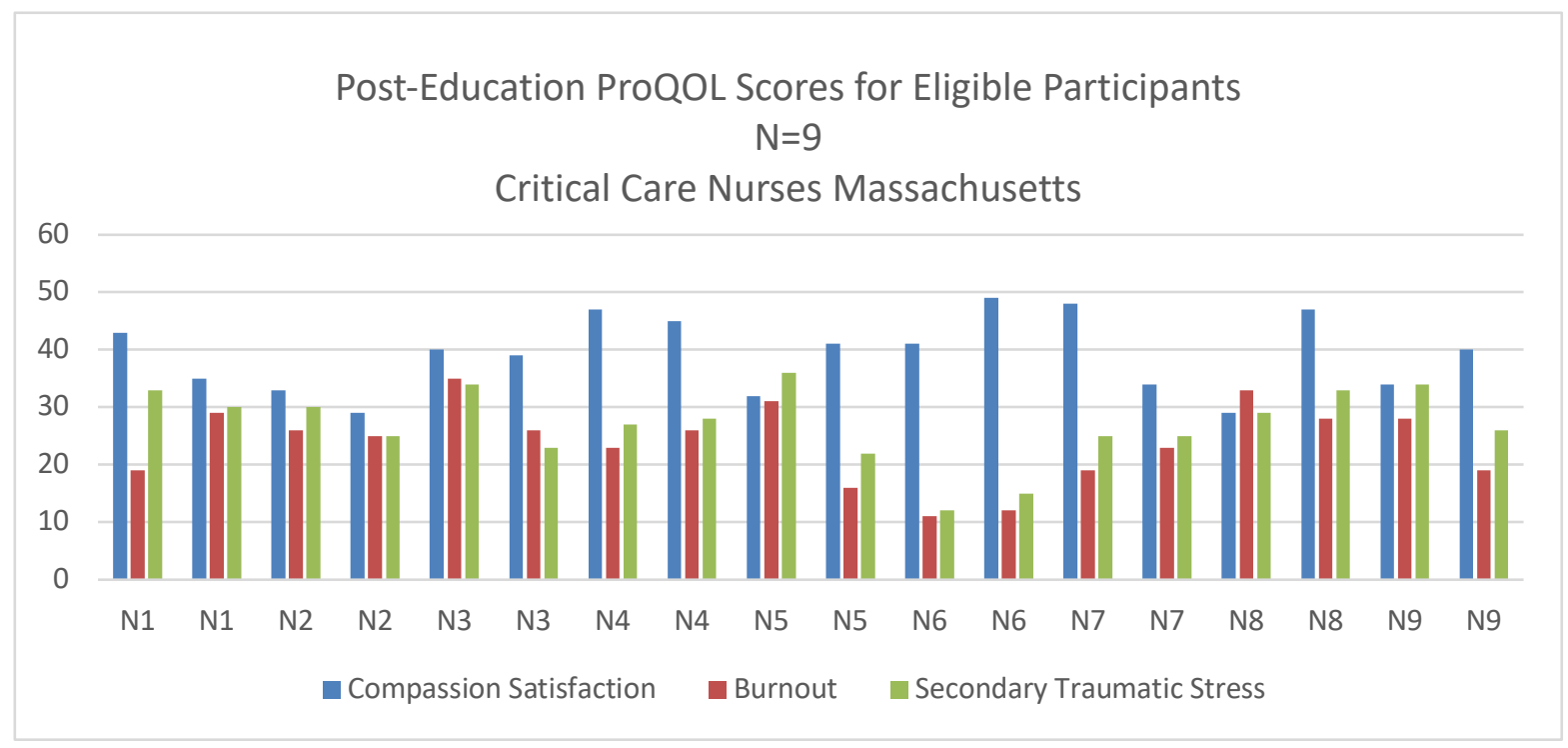




\section{Summary and Conclusions}

Compassion fatigue is a clinical problem prevalent in many intensive care units (ICU) throughout the United States. This quality improvement project aimed to uncover a knowledge gap in the clinical setting regarding a prevalent topic of compassion fatigue. The data showed that as nurses were educated about compassion fatigue, they experienced less compassion fatigue in their practice. They also reported feeling as if compassion fatigue is under discussed in the ICU, and that by participating in education regarding the topic they were more prepared to recognize symptoms of compassion fatigue and understand some relief techniques available to them. The high level of participation may indicate the concept was intriguing to the nurses and score averages for each domain suggests evidence that for a moderate amount of burnout and secondary traumatic stress experienced in this sample. The completion of this project provided the nurses with a better sense of compassion fatigue, as well as positively impacted their mental health as shown by the data. At the end of the project participating nurses felt a greater sense of the impact of compassion fatigue on the healthcare system, the negative impact on their mental health, and learned positive coping strategies to use in their practice. Some of the challenges encountered in completing this project include conducting the educational session during the work shift, difficulty in communicating content virtually, and some participant challenges with recommendations for creating a unique identifier for use throughout the project. 


\section{Recommendations and Implications for Advanced Nursing Practice}

The APRN (Advanced practice registered nurse) role has many diverse expectations, however at the forefront is education. Advanced practice registered nurses in any clinical setting provide education to patients, nurses, midlevel colleagues, physicians, and other clinical personnel. It is crucial that APRNs understand their role in providing education on clinical problems to improve patient outcomes, quality of patient care, as well as the health of those they work alongside. This project provides evidence that compassion fatigue is a clinical problem in the ICU. APRNs should utilize this information to provide resources to nurses in their own clinical settings. Recalling the pandemic, it is imperative that APRNs understand the amount of stress internally and externally given to nurses at the bedside daily. Providing relief measures is at the forefront of compassion fatigue education priorities for the APRN to assist the mental health of their colleagues. It is suggested that APRNs reflect on the project results, successes, and challenges to develop new strategies and seek methods that have the potential for targeted education and clinical practice interventions that support the complex environments of a critical care nurses suffering from compassion fatigue. 


\section{References}

American Nurses Association (2017). Healthy nurse, healthy nation. Retrieved at: https://www.nursingworld.org/practice-policy/hnhn/

Boyle D. A., (2015). Compassion fatigue: The cost of caring. Nursing 2015 45(7), 49-51. Balinbin, C. B. V., Balatbat, K. T. R., Balayan, A. N. B., Balcueva, M. I. C., Balicat, M. G. B., Balidoy, T. A. S., ... \& Torres, G. C. S. (2020). Occupational determinants of compassion satisfaction and compassion fatigue among Filipino registered nurses. Journal of clinical nursing, 29(5-6), 955-963. https://doi.org/10.1111/jocn.15163

Carroll, D. E. (2017). Compassion fatigue in hospice nursing: A program development Master's Theses, Dissertations, Graduate Research and Major Papers Overview. 190.

Christodoulou-Fella, M., Middleton, N., Papathanassoglou, E. D., \& Karanikola, M. N. (2017). Exploration of the association between nurses' moral distress and secondary traumatic stress syndrome: implications for patient safety in mental health services. BioMed research international, 1-19. . https://doiorg.ric.idm.oclc.org/10.1155/2017/1908712

Cocker, F., \& Joss, N. (2016). Compassion fatigue among healthcare, emergency and community service workers: A systematic review. International Journal of Environmental Research and Public Health, 13(6), 618. https://doi.org/10.3390/ijerph13060618 
Coetzee, S., Laschinger, H. (2017). Toward a comprehensive, theoretical model of compassion fatigue: An integrative literature review. Nursing \& Health Sciences 20(1), 4-15

Davis, L. (2013). “Dignity Health Survey Finds Majority of Americans Rate Kindness as Top Factor in Quality Health Care.” News release, November 13, 2013.

Figley (2012). Basics of Compassion Fatigue. Encyclopedia of Trauma. Sage Publications.

Gonzalez, Justina (2016). Exploring the presence of moral distress in critical care nurses. Master's Theses, Dissertations, Graduate Research and Major Papers Overview. 184. https://digitalcommons.ric.edu/etd/184

Harris, C., Griffin, M. (2015). Nursing on Empty. Journal of Christian Nursing 32(2),8087, doi:10.1097/cnj.000000000000015

Henson, J. S. (2020). Burnout or compassion fatigue: A comparison of concepts. Medsurg Nursing, 29(2), 77-95.

Heritage B, Rees C. S, Hegney D.G. (2018) The ProQOL-21: A revised version of the Professional Quality of Life (ProQOL) scale based on Rasch analysis. PLOS ONE 13(2): e0193478. https://doi.org/10.1371/journal.pone.0193478

Joinson, C. (1992). Coping with compassion fatigue. Nursing, 22(4):116, 118-9, 120. PMID: 1570090 .

Mason, V. M., Leslie, G., Clark, K., Lyons, P., Walke, E., Butler, C., \& Griffin, M. (2014). Compassion Fatigue, Moral Distress, and Work Engagement in Surgical Intensive Care Unit Trauma Nurses._Dimensions of Critical Care Nursing, 33 (4), 215-225. https://doi-org.ric.idm.oclc.org/10.1097/DC. 
Mattioli, D., Walters, L., \& Cannon, E. J. (2018). Focusing on the caregiver: compassion fatigue awareness and understanding. Medsurg nursing, 27(5), 323-328.

Melnyk, B. M., Orsolini, L., Tan, A., Arslanian-Engoren, C., Melkus, G. D. E., DunbarJacob, J., ... \& Lewis, L. M. (2018). A national study links nurses’ physical and mental health to medical errors and perceived worksite wellness. Journal of Occupational and Environmental Medicine, 60(2), 126-131. https://doi.org/10.1097/JOM.0000000000001198

Nolte, A. G., Downing, C., Temane, A., \& Hastings-Tolsma, M. (2017). Compassion fatigue in nurses: A metasynthesis. Journal of clinical nursing, 26(23-24), 43644378. https://doi.org/10.1111/jocn.13766

Perregrini M. (2019). Combating compassion fatigue. Nursing, 49(2):50-54. https://doi.org/10.1097/01.NURSE.0000552704.58125.fa. PMID: 30676560.

Rosch, P. J. (2001). The quandary of job stress compensation. Health and Stress, 3(1), 14.

Sacco, T., Ciurzynski, S., Harvey, M., Ingersoll, G. (2015). Compassion satisfaction and compassion fatigue among critical care nurses. Critical Care Nurse 35(4), 32-42. https://doi.org/10.4037/ccn2015392

Sorenson, et al., (2017). An evolutionary concept analysis of compassion fatigue. Journal of Nursing Scholarship 49(5). 557-563. https://doi.org/10.1111/jnu.12312

Stamm, B.H. (2010). The concise ProQOL manual, 2nd Ed. Pocatello, ID: ProQOL.org.

Stamm, B.H. (2016, January). Comprehensive bibliography of documents specifically using the ProQOL Measure. Retrieved at:www.proqol.org. 
Todaro-Francheschi, V. (2013). Critical care nurses' perceptions of preparedness and ability to care for the dying and their professional quality of life. Dimensions of Critical Care Nurses, 32 (4), 184-90.

Trzeciak, S., Mazzarelli, A., \& Booker, C. (2019). Compassionomics: The revolutionary scientific evidence that caring makes a difference. Social Enterprise.

van Mol, M. M., Kompanje, E. J., Benoit, D. D., Bakker, J., \& Nijkamp, M. D. (2015). The prevalence of compassion fatigue and burnout among healthcare Ppofessionals in intensive care units: A systematic review. PloS one, 10(8), e0136955. https://doi.org/10.1371/journal.pone.0136955

Viswanathan, M., Golin, C., Jones, C., Ashok, M., Blalock, S., Wines, R., CokerScwimmer, E. (2012). Interventions to improve adherence to self-administered medications for chronic diseases in the United States: A systematic review. Annals of Internal Medicine 157(11), 785-95.

Vivian, E., Oduor, H., Arceneaux, S. R., Flores, J. A., Vo, A., \& Madson Madden, B. (2019). A cross-sectional study of perceived stress, mindfulness, emotional selfregulation, and self-care habits in registered nurses at a tertiary care medical center. SAGE Open Nursing, 5, 2377960819827472.

Winters, A. (2018). Secondary traumatic stress and compassion fatigue: A guide for childbirth professionals when the infant dies. International Journal of Childbirth Education, 33(3), 46-50.

World Health Organization. (2019, May 15). What do we mean by self-care? Retrieved at: https://www.who.int/reproductivehealth/self-care 


\section{Appendix A}

\begin{tabular}{|c|c|c|c|c|c|c|}
\hline \multirow[b]{2}{*}{ Variable $^{a}$} & \multicolumn{3}{|c|}{ Burnout } & \multicolumn{3}{|c|}{ Secondary traumatic stress } \\
\hline & $t$ score, mean (SD) & $\mathrm{n}$ & $P^{\mathrm{b}}$ & $t$ score, mean (SD) & $\mathrm{n}$ & $P^{\mathrm{b}}$ \\
\hline $\begin{array}{l}\text { Age, y } \\
20-29 \\
30-39 \\
40-49 \\
50+ \\
\text { Missing } \\
\end{array}$ & $\begin{array}{l}50.0(8.1) \\
49.4(10.9) \\
54.1(12.7) \\
45.7(7.8)\end{array}$ & $\begin{array}{l}86 \\
39 \\
43 \\
37 \\
16 \\
\end{array}$ & .002 & $\begin{array}{l}51.2(10.3) \\
47.8(7.8) \\
53.1(11.3) \\
45.8(8.3)\end{array}$ & $\begin{array}{l}90 \\
39 \\
43 \\
38 \\
11 \\
\end{array}$ & $\begin{array}{l}.04 \\
.01\end{array}$ \\
\hline $\begin{array}{l}\text { Acuity level } \\
\text { Single } \\
\text { Mixed } \\
\text { Missing } \\
\end{array}$ & $\begin{array}{l}48.2(9.7) \\
52.6(9.9)\end{array}$ & $\begin{array}{r}132 \\
64 \\
25 \\
\end{array}$ & .004 & $\begin{array}{l}48.7(10.4) \\
52.4(8.9)\end{array}$ & $\begin{array}{r}135 \\
66 \\
20\end{array}$ & .01 \\
\hline $\begin{array}{l}\text { Nursing management change } \\
\text { Yes } \\
\text { No } \\
\text { Missing }\end{array}$ & $\begin{array}{l}53.1(10.7) \\
47.7(8.7)\end{array}$ & $\begin{array}{l}93 \\
97 \\
31 \\
\end{array}$ & & $\begin{array}{l}50.6(10.5) \\
49.4(10.0)\end{array}$ & $\begin{array}{r}94 \\
100 \\
27\end{array}$ & \\
\hline $\begin{array}{l}\text { System/practice change } \\
\text { Redesign } \\
\text { Yes } \\
\text { No } \\
\text { Missing }\end{array}$ & $\begin{array}{l}51.0(10.1) \\
49.0(9.8)\end{array}$ & $\begin{array}{l}75 \\
95 \\
51\end{array}$ & & $\begin{array}{l}51.9(10.8) \\
48.3(9.7)\end{array}$ & $\begin{array}{l}74 \\
99 \\
48\end{array}$ & .02 \\
\hline
\end{tabular}

${ }^{a}$ Missing indicates that response was left blank or respondent selected decline to answer. For acuity level, single indicates intensive care unit; mixed indicates intensive care unit/progressive care unit or intensive/progressive/general care unit.

Significant according to Scheffé post hoc comparisons.

\section{Appendix B}

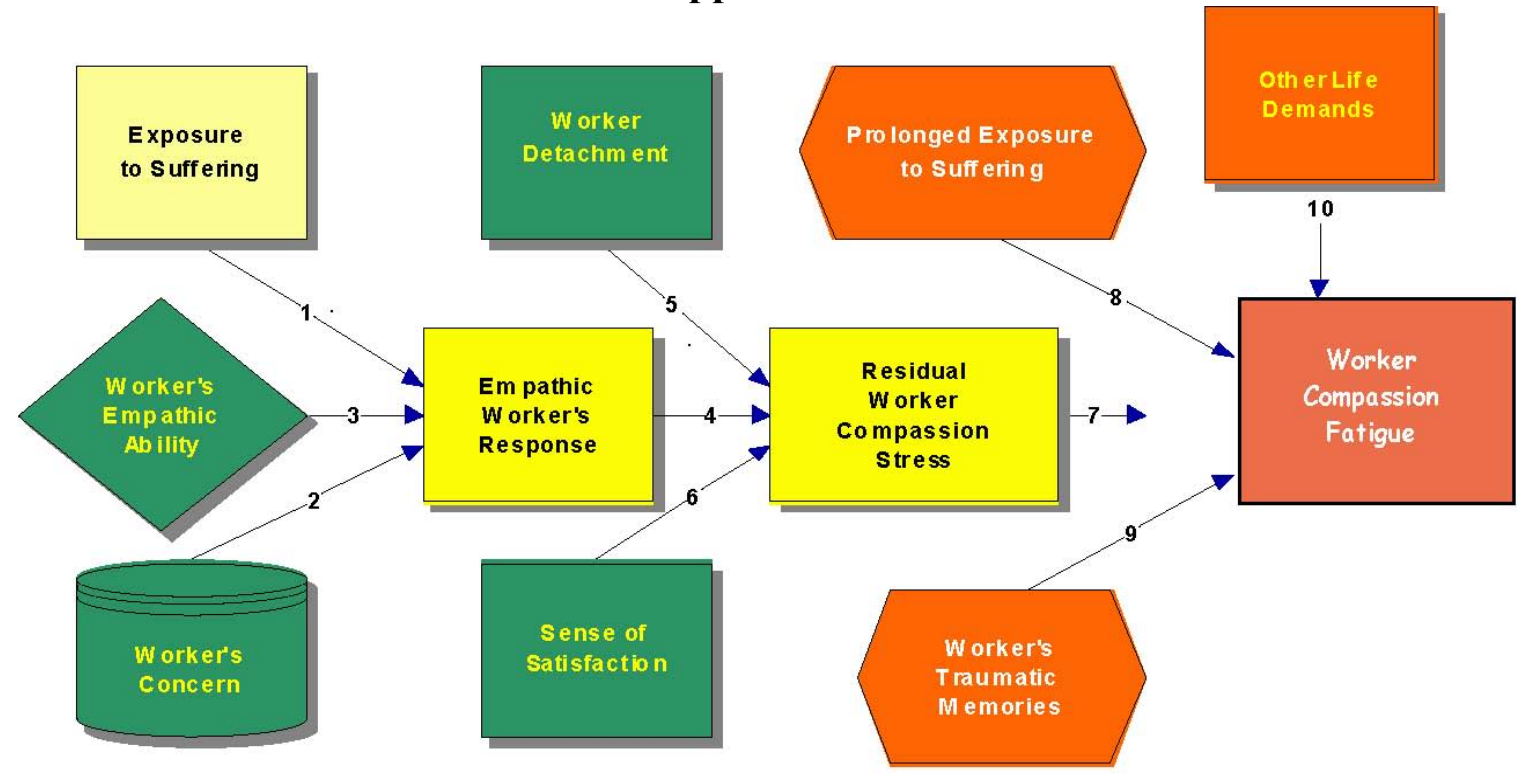

Compassion Fatigue Process (Figley, 2001) 


\section{Appendix C \\ Compassion Fatigue in Critical Care Nurses}

\section{An Educational Quality Improvement}

\section{Project}

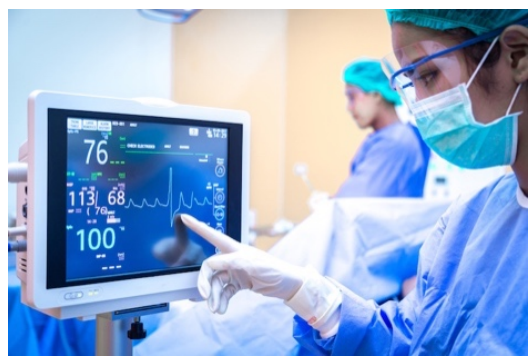

Compassion fatigue is defined as the progressive and cumulative outcome of prolonged, continuous, and intense contact with patients, self-utilization, and exposure to multidimensional stress leading to a compassion discomfort that exceeds nurse's endurance levels (Coetzee \& Klopper, 2010).

You are formally invited to participate in an anonymous survey and educational session regarding compassion fatigue.

Education includes relief techniques to implement in your practice.

Please join me to bring your voice to the data about the emotional consequences of caring in the ICU.

Participation is voluntary and anonymous.

Accepting participants March 2021.

Educational session planned for late March/ early April 2021.

Please feel free to contact me in regard to any questions you may have.

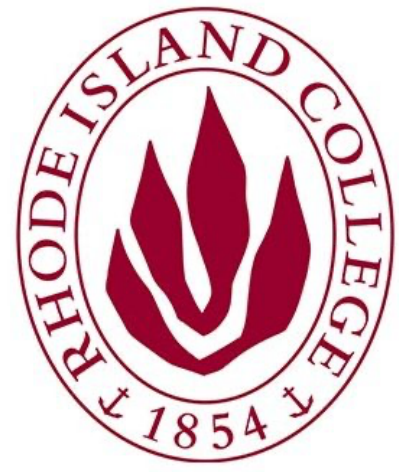

Natasha M. Teixeira BSN-RN, CCRN

Graduate Student Nurse Practitioner

Rhode Island College

ngarcia5013@email.ric.edu

$\underline{\text { Rhode Island College IRB \# 2021-2122 }}$ 


\section{Appendix D}

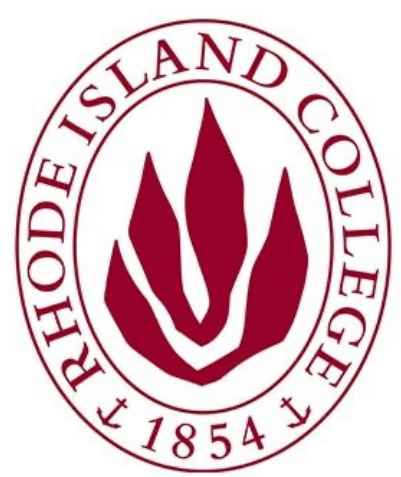

Attention Critical Care Nurse at South Shore Hospital,

My name is Natasha Teixeira BSN, RN, CCRN and I am a master's nurse practitioner student at Rhode Island College. Part of my educational training consists of a quality improvement project designed to target a problem in nursing and offer a solution. For my project I have chosen to educate critical care nurses on compassion fatigue and offer an educational session to decrease symptoms of compassion fatigue in your practice.

\section{Study Information}

\section{Participation is completely voluntary.}

In this email there is a link to the Qualtrics ProQOL. Qualtrics is a system similar to SurveyMonkey that allows users to complete a survey, and lets the administrator analyze the data of the participants results. The ProQOL is a validated tool used to measure compassion fatigue. This initial survey will serve as a baseline for your own individual report of the level of compassion fatigue you experience in your practice. Each participant will be asked to create a user specific unique identifier, such as a series of numbers or letters that are meaningful to you (e.g., 7121920). The survey will remain active for two weeks for you to be able to complete at your convenience and should take approximately 10-15 minutes to complete.

Next, within the next couple of weeks there will be an e-mail sent to you with a Zoom link to an educational session regarding compassion fatigue, signs and symptoms, clinical significance, mitigation of symptoms in your practice, and ways to improve your mental health in the clinical setting. This should take approximately fifteen minutes. A short five question survey about the session will also be given.

Finally, one month after the educational session, an email with a new link to the ProQOL survey will be sent to you. This will be the same survey that you initially completed. You will need to enter the user specific code you created previously. The purpose of the second ProQOL is to identify if the educational session had any impact in your current level of compassion fatigue.

All results are anonymous and will not be shared with your employer or anyone else, except for the project team.

Lastly, and most importantly, thank you for what wonderful work you do every day at the bedside. Your hard work does not go unnoticed, and the emotional toll you endure while caring for strangers needs to be addressed. Please join me in bringing to light the emotional cost of nursing. If you have any questions, please feel free to contact me at ngarcia_5013@email.ric.edu. 
Sincerely,

Natasha M. Teixeira

Natasha M. Teixeira BSN-RN, CCRN 
Appendix E

\section{PROFESSIONAL QUALITY OF LIFE SCALE (PROQOL)}

COMPASSION SATISFACTION AND COMPASSION FATIGUE

$$
\text { (PROQOL) VERSION } 5 \text { (2009) }
$$

When you [help] people you have direct contact with their lives. As you may have found, your compassion for those you [help] can affect you in positive and negative ways. Below are some-questions about your experiences, both positive and negative, as a [helper]. Consider each of the following questions about you and your current work situation. Select the number that honestly reflects how frequently you experienced these things in the last 30 days.

I=Never 2=Rarely 3=Sometimes 4=Often $\quad$ 5=Very Often

I. I am happy.

2. I am preoccupied with more than one person I [help].

3. I get satisfaction from being able to [help] people.

4. I feel connected to others.

5. I jump or am startled by unexpected sounds.

6. I feel invigorated after working with those I [help].

7. I find it difficult to separate my personal life from my life as a [helper]

8. I am not as productive at work because I am losing sleep over traumatic experiences of a person I [help].

9. I think that I might have been affected by the traumatic stress of those I [help].

10. I feel trapped by my job as a [helper].

II. Because of my [helping], I have felt "on edge" about various things.

12. I like my work as a [helper].

13. I feel depressed because of the traumatic experiences of the people I [help].

14. I feel as though I am experiencing the trauma of someone I have [helped].

15. I have beliefs that sustain me.

16. I am pleased with how I am able to keep up with [helping] techniques and protocols.

17. I am the person I always wanted to be.

18. My work makes me feel satisfied.

19. I feel worn out because of my work as a [helper].

20. I have happy thoughts and feelings about those I [help] and how I could help them.

21. I feel overwhelmed because my case [work] load seems endless.

22. I believe I can make a difference through my work.

23. I avoid certain activities or situations because they remind me of frightening experiences of the people I [help].

24. I am proud of what I can do to [help].

25. As a result of my [helping], I have intrusive, frightening thoughts.

26. I feel "bogged down" by the system.

27. I have thoughts that I am a "success" as a [helper].

28. I can't recall important parts of my work with trauma victims.

29. I am a very caring person.

30. I am happy that I chose to do this work.

(c) B. Hudnall Stamm, 2009-2012. Professional Quality of Life: Compassion Satisfaction and Fatigue Version 5 (ProQOL). www.proqol.org. This test may be freely copied as long as (a) author is credited, (b) no changes are made, and (c) it is not sold. Those interested in using the test should visit www.proqol.org to verify that the copy they are using is the most current version of the test. 


\section{Appendix F}

\section{Permission to Use the ProQOL}

Thank you for your interest in using the Professional Quality of Life Measure (ProQOL). Please share the following information with us to obtain permission to use the measure:

Please provide your contact information:

Email Address

ngarcia_5013@email.ric.edu

Name

Natasha Teixeira

Organization Name, if applicable

Rhode Island College

Country

United States

Please tell us briefly about your project:

Quality Improvement Project.

Assessment of compassion fatigue in critical care nurses using the ProQOL scale.

ProQOL score pre-education. Education on limiting effects of compassion fatigue. ProQOL score post-education.

Master's Thesis Project NP.

What is the population you will be using the ProQOL with?

Critical care nurses.

In what language/s do you plan to use the ProQOL?

Listed here are the languages in which the ProQOL is currently available

(see https://proqol.org/ProQol_Test.html). If you wish to use a language not listed here, please select "Other" and specify which language/s.

English

The ProQOL measure may be freely copied and used, without individualized permission from the ProQOL office, as long as:

You credit The Center for Victims of Torture and provide a link to www.ProQOL.org;

It is not sold; and

No changes are made, other than creating or using a translation, and/or replacing "[helper]" with a more specific term such as "nurse."

Note that the following situations are acceptable:

You can reformat the ProQOL, including putting it in a virtual format

You can use the ProQOL as part of work you are paid to do, such as at a training: you just cannot sell the measure itself

Does your use of the ProQOL abide by the three criteria listed above? (If yes, you are free to use the ProQOL immediately upon submitting this form. If not, the ProQOL office will be in contact in order to establish your permission to use the measure.) 